\title{
Evaluation of Placer Deposits in Ghana: a Case Study of the Kwabeng Placer Gold Deposit North Western Flank of Atewa Range, Eastern Region, Ghana
}

\author{
Richmond Nkrumah ${ }^{1}$ Kofi Agyemang, Dr. Gordon Foli ${ }^{3}$, Prof. Simon K.Y Gawu ${ }^{4}$, Prof. Prosper M. Nude ${ }^{5}$ \\ ${ }^{1}$ CG Minerals Ghana Limited, Nsutam, Ghana \\ ${ }^{2}$ Kibi Goldfields Ghana limited, Osino, Ghana \\ ${ }^{3 \& 4}$ Kwame Nkrumah University of Science and Technology \\ ${ }^{5}$ University Of Ghana, Legon, Accra
}

\begin{abstract}
The estimation of Mineral Resources/Reserves (MR) together with the quantification of the distribution of metallurgical attributes provide strong evaluation of the large alluvials gold deposits within Kwabeng and its surrounding, which occurs along the north western flank of the famous Atewa Range. This reduces the risk arising from uncertainties within the ore body as far as geological and metallurgical information are concern and also improve decision making process during the production stage of the mining project. Hand dug Pits data formed the basis for the estimation of the MR as well as the determination of the spatial distribution of the metallurgical parameters of the Kwabeng deposits. A typical grid density of $200 \mathrm{~m} \times 50 \mathrm{~m}$ was used for the pitting. Detailed logging of pit samples together with processing provided first hand information concerning the metallurgical behavior of the gold bearing gravels and subsequent distribution of these parameters. The estimation of the MR have been based on an initial estimation of the gold grade and gravel section using the inverse distance weighting (IDW) technique and subsequent estimation of the resources using the volume and mean grade of the ore. A total volume of $19328000 \mathrm{~m} 3$ gold bearing gravels were estimated at average grade of $0.46 \mathrm{~g} / \mathrm{m} 3$ and fine ounces of $261,728 \mathrm{oz}$ based on the gold fines of 920 for the alluvial gold within the area. The gold within the study is usually coarse in nature with majority of the coarse gold occurring at the upstream of the drainages in the area. Clayey materials also represent large portion of the gold bearing gravels in almost all the sampled areas.
\end{abstract}

Keywords: Placer deposit, Resource Evaluation, Kwabeng, Atewa Range.

\section{Background}

\subsection{INTRODUCTION}

Alluvial gold deposits occurred throughout the country in favorable areas overlying Birimian metavolcanics and metasediments rocks. The vast majority of historical gold production from Ghana prior to the 20th century came from a myriad of small streams and rivers draining areas with underlying oxide and primary gold deposits (Hilson, 2002). In addition, several of the major rivers have been mined with dredges starting in the early 1900s and in the 1990s, large alluvial operations were started up on river valleys in several alluvial gold districts. With the recent increase in the gold price over the past several years, the amount of small-scale gold mining, primarily of alluvial deposits, has increased dramatically throughout Ghana and especially in places like the Atewa Range, where substantial alluvial gold resources are known. Those of the Offin alluvial gold occurred along the River Offin, north of Dunkwa in the central region of Ghana. As reported by Levich (2010), the lower gold bearing gravel lies on top of weathered Birimian with thickness ranging between 2-6m and is overlain by similar thickness of gravel barren overburden consisting of silt and clay materials. The gold bearing gravels of the Offin River deposit contains large pebbles to cobbles size clast up to $15 \mathrm{~cm}$ in diameter, in matrix of quartz and heavy minerals.

The large alluvial occurrences along the flank of the Atewa range also represent some of the largest alluvial gold deposit in the country. The deposits are found within the valleys and are covered by silt and clay-rich overburden. The overburden is massive and is in sharp contact with the underlying gravels which also filled most of the valleys within the area.

The overburden within the area is very thick and sometimes can be deep as 4-6m although some few areas may record very thin overburden where the gravel section seems to appear on the surface (Griffis et al 1989).

The Kibi area has long been known for very significant alluvial gold and although some dredging was attempted within the Upper Birimian, most of the production has come from dozens of the smaller drainages all along the flanks of the Atewa Range. The most famous historical site was at Pusupusu where artisanal mining took place for generations and several sluicing operations were carried out in the early 1900s. Junner (1935) indicated that the PusuPusu area features boulder gravels up to $2.5 \mathrm{~m}$ thick and these are overlain by clay/silt overburden of a similar thickness; very coarse nuggets (up to $8 \mathrm{oz}$ ) and recorded production from mining companies during 1920 s was more than $267 \mathrm{~kg}$ from about 298,000 cubic meters of gravel with a recovered grade of 0.8 to $0.9 \mathrm{~g} / \mathrm{m}^{3}$

A very similar pattern seems to prevail in most of the valleys along the Atewa Range; these include the 
established resources along the Awusu (Kwabeng) Merepong (Pameng), upper Birim (Apapam) and Akusu (Osino/Saaman) drainages. Gold-bearing basal gravels $1-3 \mathrm{~m}$ thick sit on top of weathered Birimian units, mainly metasediments, and the gravels are invariably overlain by barren sands, silt and clay of comparable thickness.

The large alluvial gold resources of Kwabeng Mine are located along Awusu River and its tributaries within favorable geological environments of primary gold deposits. Which is believed to have originated from the weathering of near auriferous quartz veins which are known to occur not only in the headwaters of the major streams from Atewa Range but also in some of the lower valleys (Griffis et al., 1989). This is evident by the large coarse gold recovered from the Goldenrae plant on the Kwabeng concession.

Most alluvial gold projects have failed basically due to several factors which are common within the mining industry. But those that have contributed significantly to the failure as far as placer deposit is concern is the poor resource estimation and metallurgical factors reporting (Rae et al, 2006). The issue of placer deposit assessment has resulted in the collapse of many alluvial mines than any other reason. In addressing some of the issues concerning placer deposits assessments, Boostein (2013) outlined some factors one needs to consider when evaluating alluvial deposits. According to him, there must be a relatively large sample size; because most of the deposits are composed of different sizes of gravels which makes it very difficult to obtain a representative sample. Also higher values of gold within certain areas distort the calculation of the resource. In addition the values of the gold recorded must be observed and noted with items associated with gravels such as the boulder sizes, volume of clay, bedrock conditions, and any other physical properties that may have impact on the mining and processing the ore.

\subsection{Study area}

The study area (Fig 1) is located at the northwestern flank of the Atewa Range. The property is measured $44 \mathrm{~km}^{2}$ and is bounded by latitudes $6^{\circ} 20^{\prime}, 6^{\circ} 16^{\prime} \mathrm{N}$ and Longitude $0^{\circ} 38^{\prime}, 0^{\circ} 36^{\prime} \mathrm{W}$ and lies within the Atewa district in the Eastern Region of Ghana.

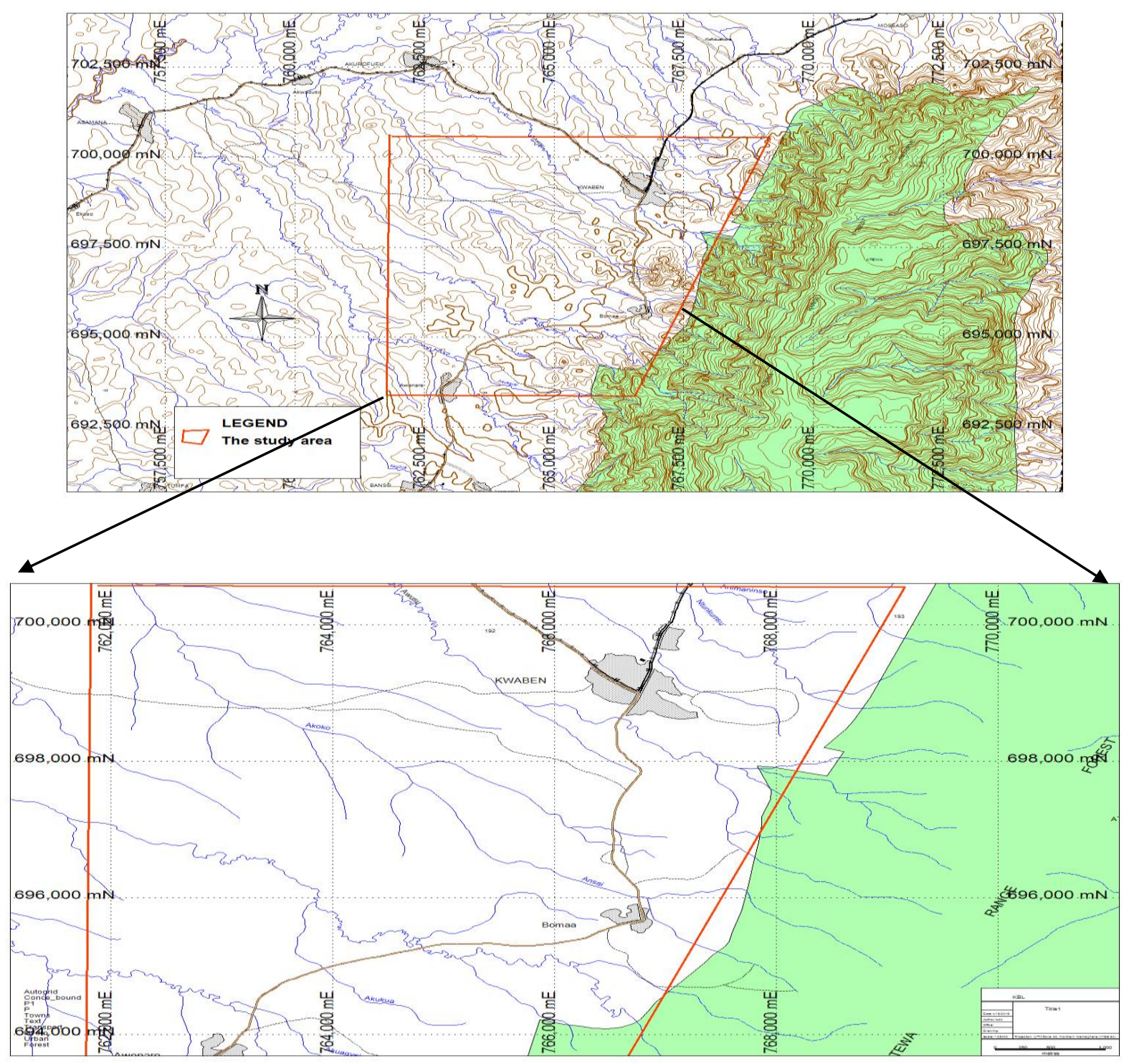

Fig 1. Location map of the study area. 


\subsection{Geology of the area}

The Kwabeng area is within the Kibi gold belt which forms part of the Birimian terranes in southwestern Ghana. A thorough systematic geological mapping of southern Ghana was carried mainly in the period 1920-1940 (Kesse, 1990) . According to Kesse 1990, this work recognized the existence of relatively long narrow parallel spaced northeast tending belts containing variable amounts of Precambrian, metamorphosed volcanic extrusivs and pyroclatics materials. Between these belts are intervening area representing broad sedimentary basins dominated mainly by marine clastic sediments with variable amounts of volcaniclastic units. With intervening volcanoclastic sedimentary basins dominated mainly by marine clastic sediments with variable amounts of volcaniclastic units.

The Kibi belt (Fig 2) is the easternmost belts of the Birimian rocks. It lies next (in east direction) to the wellknown prolific Ashanti belt which host most of the Birimian gold with major active gold mines located in there. According to Simone et al., (2012), the north-east trending Kibi greenstone belt is approximately $60 \mathrm{~km}$ long with it northern extension overlain by younger, flat lying sediments of the Voltain basin where as the southern extremity is truncated by a large granitoids batholiths.

The Kibi Belt geology consists of a tightly folded, slightly overturned, north north-east trending syncline featuring a variety of metavolcanics, mafic intrusions and metasediments. The western margin (where the Kwabeng deposit is situated) of the belt is dominated by steeply dipping, highly deformed and fractured metasediments, often with extensive bands of graphite. These are flanked by metavolcanic flows (mafic to intermediate) and metavolcaniclastics with interbedded metasediments; within these there are numerous shallow level mafic plutons (mostly epidiorites). In the central part of the belt, which more or less coincides with the main Birim River valley, the dominant lithologies are clastic metasediments, some of them quite coarse, whereas on the eastern margin of the belt, along the summit of the prominent Apedwa hills, mafic and intermediate to possibly felsic metavolcanics, are more widespread and appear to be overturned to the northwest. More details on the Kibi gold belt can be found in Griffis (2002).

Detailed work carried by Griffis et al., (1989) reported reveals the valleys within the area are underlain by thick sequences of alluvial deposit with several cross-cutting structures observed along the flanks of the Atewa range. With some of these inferred structures corresponding to the valleys hosting significant alluvial gold occurrences which maybe primary lode gold sources.

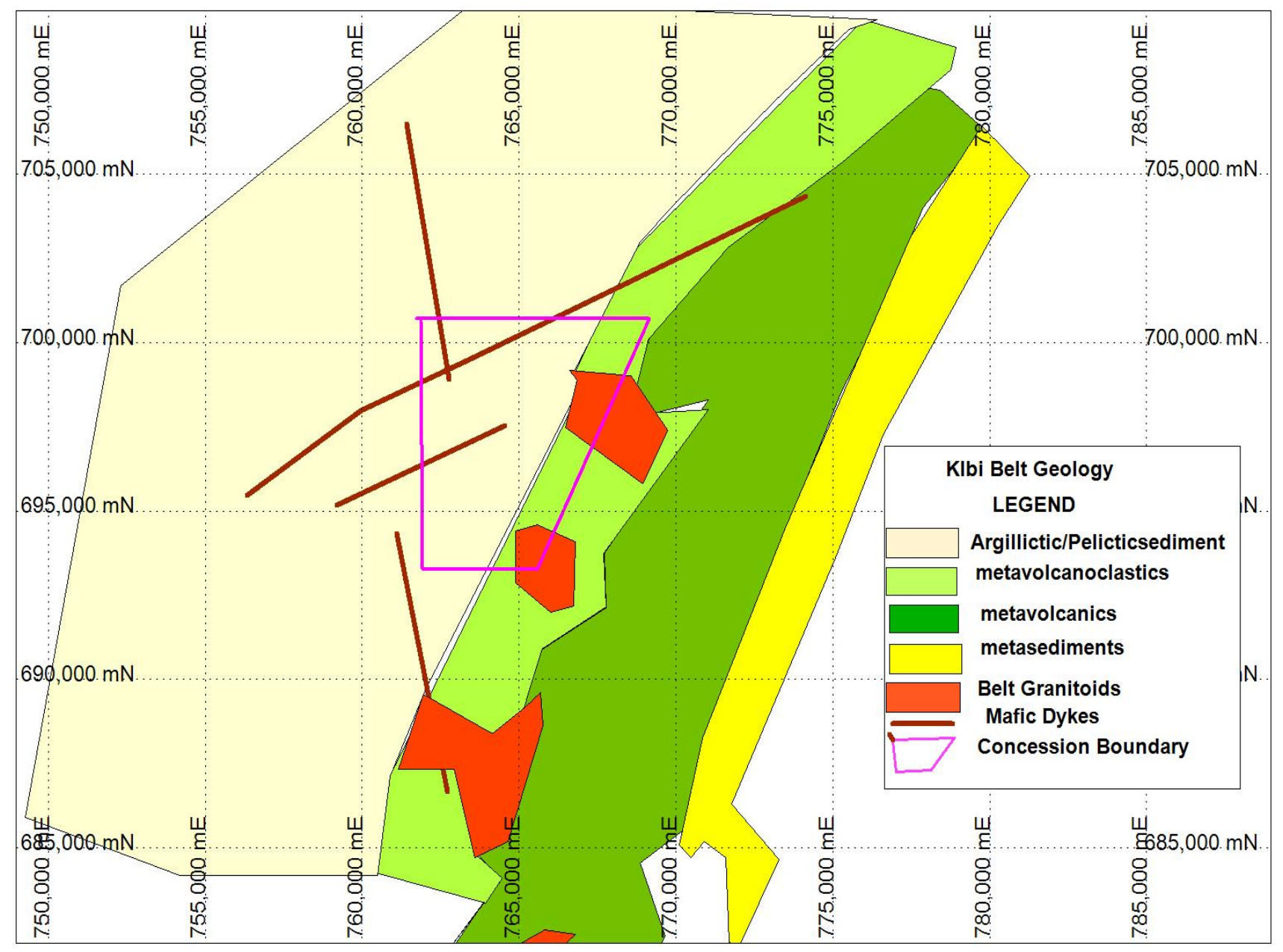

Fig 2. Kibi belt geology. 


\subsection{MATERIALS AND METHODS.}

All pits data were derived from the geological database of Kwabeng Mine . A typical hand dug tools consisting of axe, long sharp metal and spade were used for the pitting as opposed to the mechanized one which uses banka drilling machine.

\subsection{Pitting/processing of samples}

A $1 \mathrm{~m} \times 1 \mathrm{~m}$ hand dug pitting on grid density of $200 \times 50 \mathrm{~m}$ was used in getting through the overburden, gravel section and to the bed rock during the pitting activities. Hand dug pit into placer deposit is one of the oldest technique use to sample alluvial deposits.

Pitting is more reliable than drilling especially in areas where the deposit occur close to the bedrock because it gives more reliable information about various sections and also provide more representative samples (Rae et al 2006). Bulk samples from the exploration program were processed using the prospector (a small portable wash plant) where final concentrate were collected and pan. The recorded gold from the pan concentrate are then recorded in grams together with the pit ID. According to Rae et al ., (2006), it may be preferable in some cases, to utilize a cement mixer to wash each of the pit samples in order to ensure that all of the gravels are really well cleaned so that all the gold is liberated and subsequently recovered in portable Knelson bowl. However, for some large pitting programs, this method may be a little impractical to be used on routine basis but it should at least be used to check and confirm results from other pits where the gravels were processed through a Prospector.

\subsection{Data analysis}

Data analysis which forms a small portion of the overall scheme of the work, has the potential of revealing database errors which can be detrimental to the efficient reporting of resource volume, grade and classification. The histogram and box-plot have been used to graphically examine the dataset. In addition to the graphical examination, descriptive statistics were carried out to compute statistical measure such as mean, mode, variance, standard deviation etc.

\subsection{Geospatial interpolation}

Geospatial technique was used for the interpolation of the gold grade and gravel thickness of the deposit to determine the weighted average. The method used in this study is the inverse distance weighting (IDW) method which estimates spatial variability of parameters based on the weighteing of neighborhood sampled points. Several authors (e.g. Sarala et al., 2016; Al-Hassan et al., 2015; Tulay et al., 2015; Pudraet al 2013; Metternicht et al., 2003) have used the technique to analyze the spatial variability of gold grade in fluivial sediments and other soil parameters.

The idea behind IDW interpolation is based on Tobler's first law of geography (1970) which states that "All places are related, but nearly places are more related than distant places". The estimation of values for unsampled areas are primary based on the nearest point than further away sampled points. To satisfy tobler's law, IDW uses another exponential number which gives more weighting to the close points during its estimation. For the purpose of this study, exponential power of two (2) is used for the interpolation of the various parameters. This value is known to be the best exponential values that best fit the IDW estimation ( e.g Al-Hassan et al., 2015; Isaaks et, 1989).

To evaluate the accuracy of the estimation cross validation using the root mean square error (RMSE) was initiated. This validation has been recommended by authors (e.g;Tulay et al., 2015; Metternicht et al, 2003; Webster et al., 2001).

$$
R M S E=\sqrt{\frac{\perp}{N} \sum_{i=1}^{N}\left\{z\left(x_{i}\right)-\hat{z}\left(x_{i}\right)\right\}^{2}}
$$

(Metternicht et al., 2003)

$\left(\mathrm{x}_{\mathrm{i}}\right)$ is the estimated (predicted) value, the known value is represented by $\mathrm{z}, \mathrm{N}$ is the number of samples and RMSE is the root mean squared error.

Getting predictions values close to the observed values gives a small RMS error. These smaller 1 values are preferred as far as the geostatistical interpolation is concerned. Although RMS error is able to tell much about the accuracy of the estimation, errors may still exist within neighborhood sample points (Al-Hassan et al., 2015).

\subsection{Resource estimation}

The resource potential was estimated to know the amount of fine gold within the study area after the estimation of the mean gold grade and gravel thickness. The method used for the resource potential here is given as $\mathrm{P}=\mathrm{VG}$ after Chirico et al (2010), where $\mathrm{P}$ is the estimated resource potential of the study area, $\mathrm{V}$ is the volume of the gravel section (deposit) and $\mathrm{G}$ is the mean (average) grade of the deposit. The mean grade used for the final calculation of the gold resource potential was derived from the generated grade estimation from the IDW model.

\subsection{RESULTS.}

\subsection{Pit lithology}

The various sections of the pits were logged to determine the overburden thickness, gravel thickness, depth to bedrock, the overburden materials as well the gravel section lithology. The depth of most of the pits ranges from 2-6m with most section being the overburden. Overburden ranges from $0-4.8 \mathrm{~m}$ whiles the mineralized section ranges from 0.4 to $2.8 \mathrm{~m}$. The uppermost layer is mostly clay with laterite whiles the middle section comprises of quartz pebbles with silty clay or with laterite in some areas. The layer which usually ends the pit is the saprolite zone which continue as the bedrock. The various layers or sections encountered conform well with other alluvial deposits studied elsewhere (e.g Eberle et al, 2016; Jonas et al; 2017). They normally consist of three lithologically inhomogeneous units in vertical succession.

\subsection{Statistical results}

About 324 pits have been analyzed for the optimal resource estimation. Since the technique of determining normal distribution of datasets is either through graphical 
representation of the data or descriptive analysis, the histogram and box-whisker is used as the best graphical representation of the normal distribution of this geological datasets. It is important to have a normally distributed datasets before performing any inferential statistical analysis.

The graphical representation of the gold grade using the histogram and box plot show some skewness in the gold grade data. The Au grade is positively skewed as shown in Fig 3 with major outliers indicated in the box-whisker plot (Fig 5). Somewhat normal distribution was achieved after it was $\log _{10}$ transformed (Fig 4). The standard deviations, variance for the Au grade and mean grade include $0.3 \mathrm{~g} / \mathrm{m}^{3}$, $0.155 \mathrm{~g} / \mathrm{m}^{3}$ and $0.49 \mathrm{~g} / \mathrm{m}^{3}$ respectively. The minimum and maximum grades obtained values were $0 \mathrm{~g} / \mathrm{m}^{3}$ and $2.73 \mathrm{~g} / \mathrm{m}^{3}$ with a range of $2.73 \mathrm{~g} / \mathrm{m}^{3}$ as indicated in Table 1 .

Gravel section (ore zone ) shows some skeweness and various outliers as shown in the graphical histogram and box-whisker plot (Fig 7\& 8). Natural log of the gravel thickness reveals normal distribution in the datasets (Fig 9). The arithmetic mean of the gravel thickness within the area is $2.5 \mathrm{~m}$.

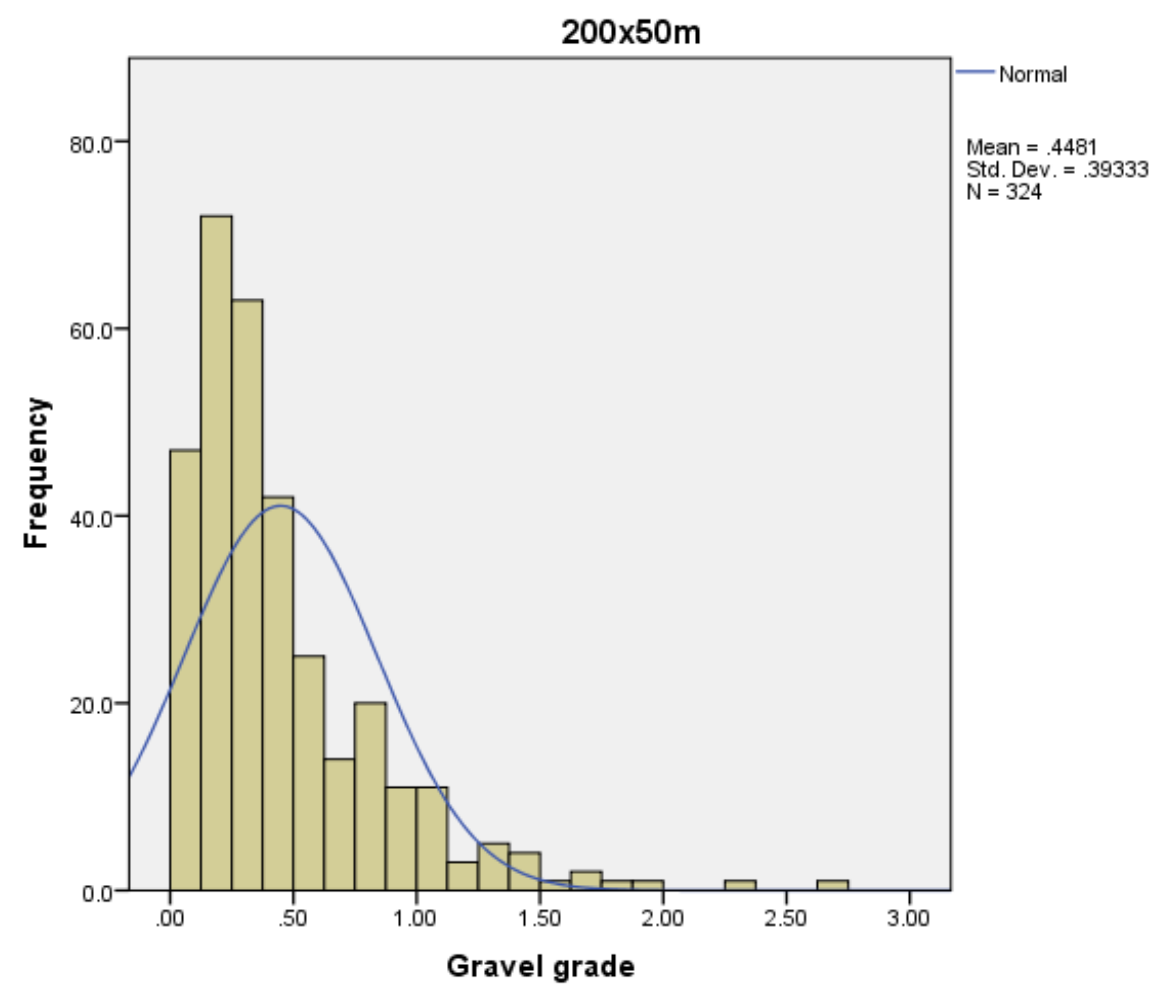

Fig 3. The histogram plot of the gold grade with a positively skewed data.

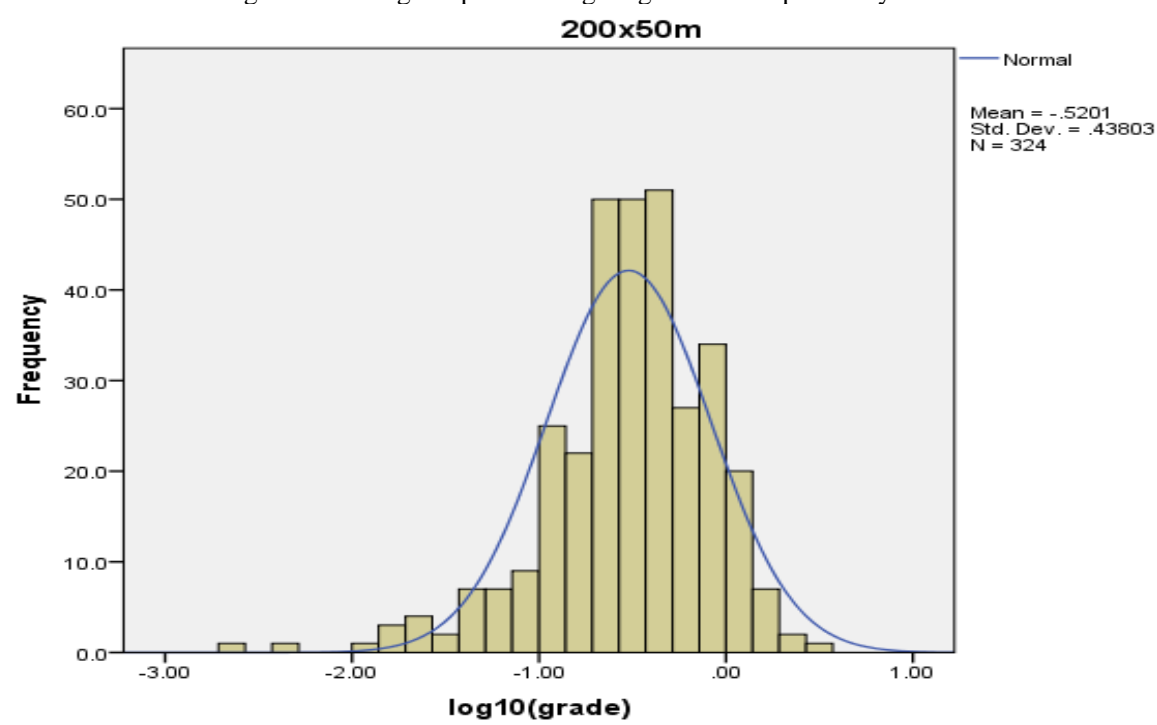

Fig 4. Histogram plot of the $\log 10$ ( gold grade) of the gravel section with some normal distribution after the natural $\log$ transformation 


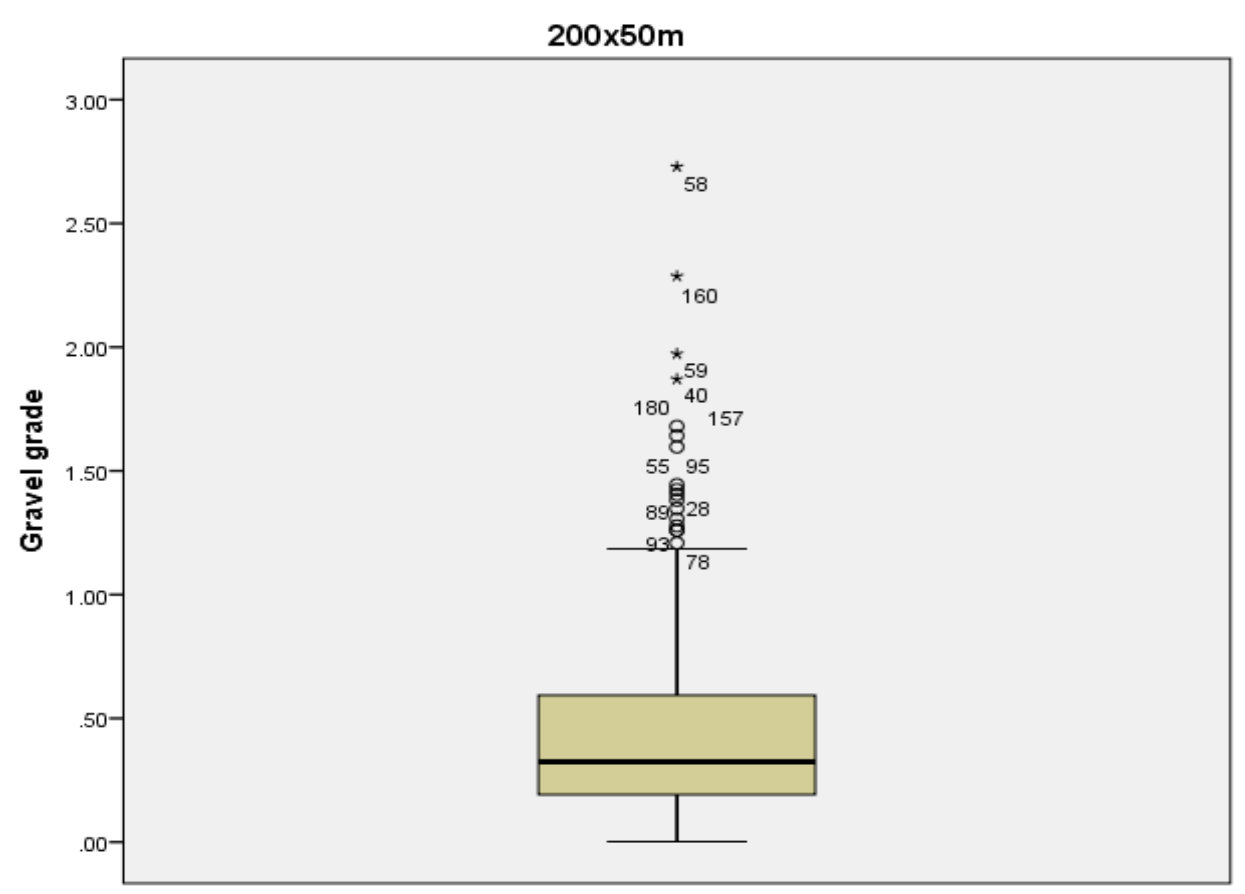

Fig 5. Box-Whisker plot of the gravel grade with major outliers

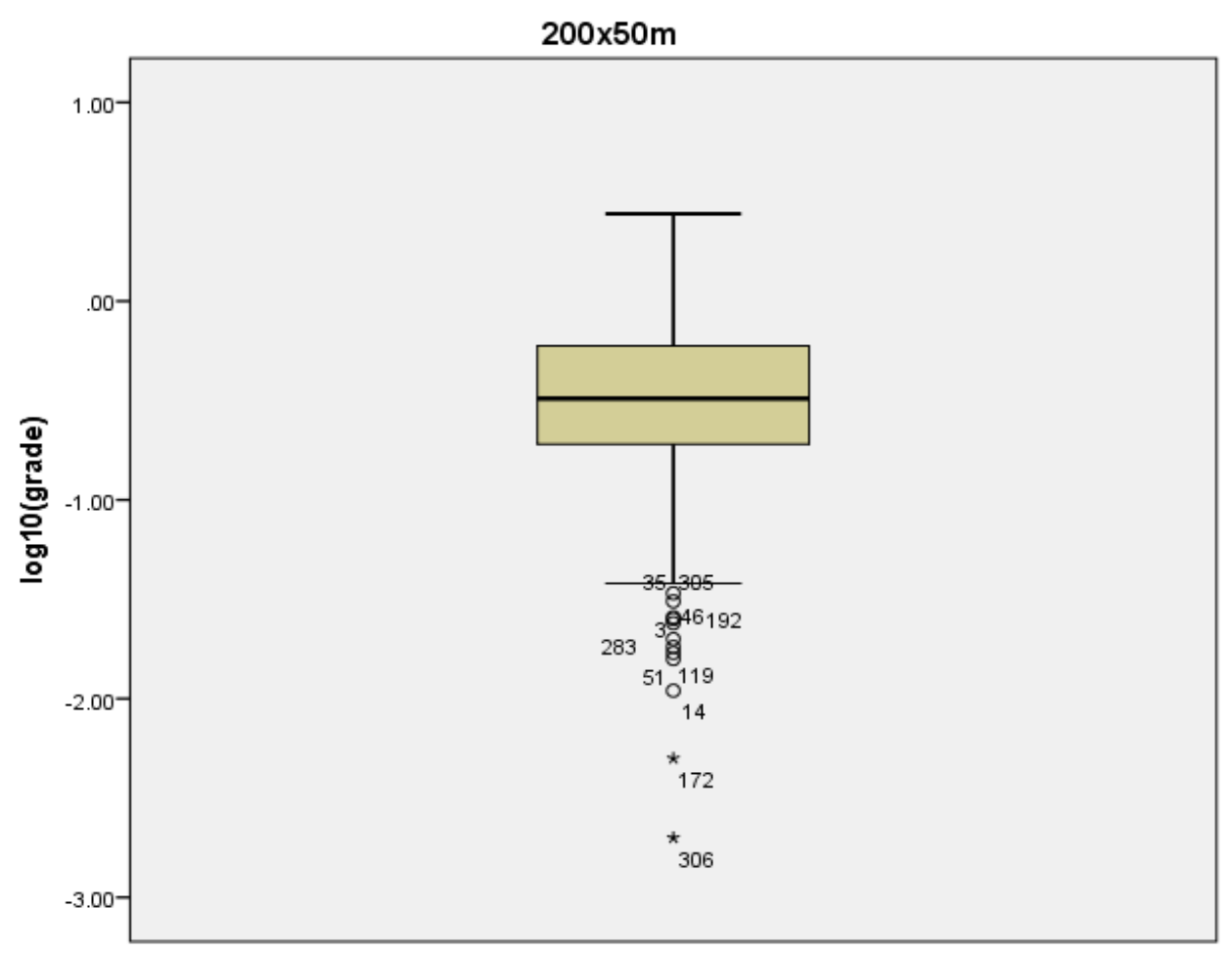

Fig 6. Log transform of the gravel grade. 


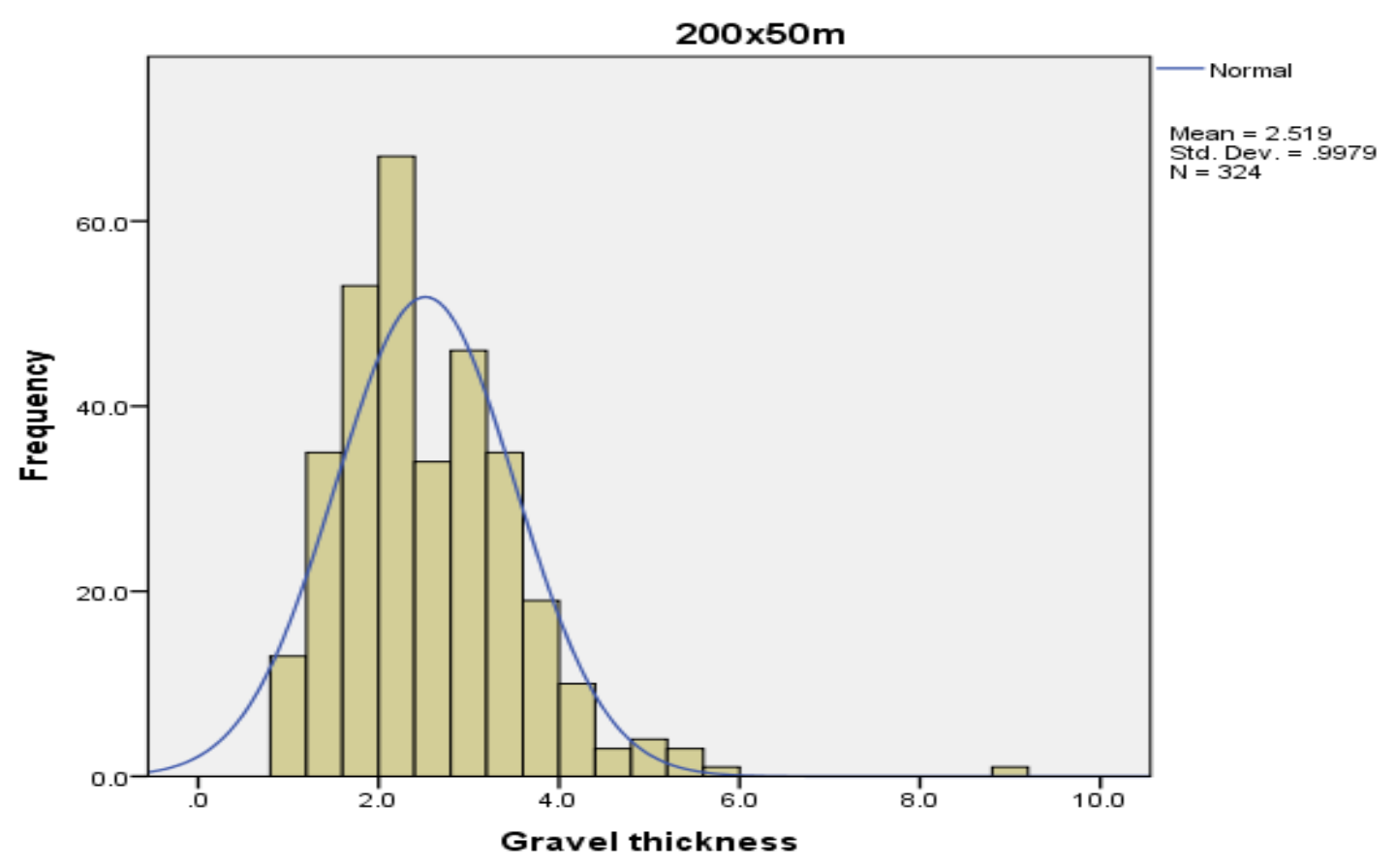

Fig 7. Histogram plot of the gravel thickness

$200 \times 50 m$

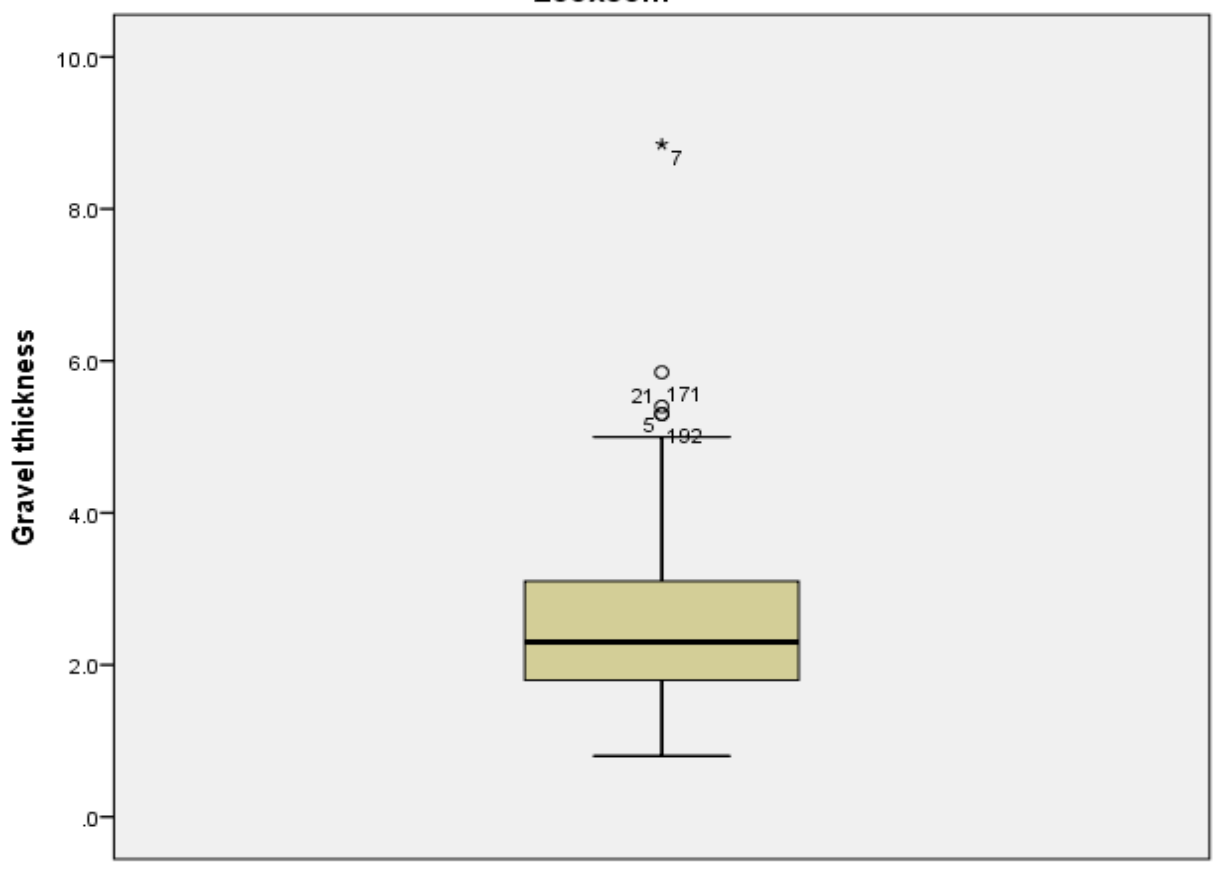

Fig 8. Box-Whisker plot of the gravel thickness 


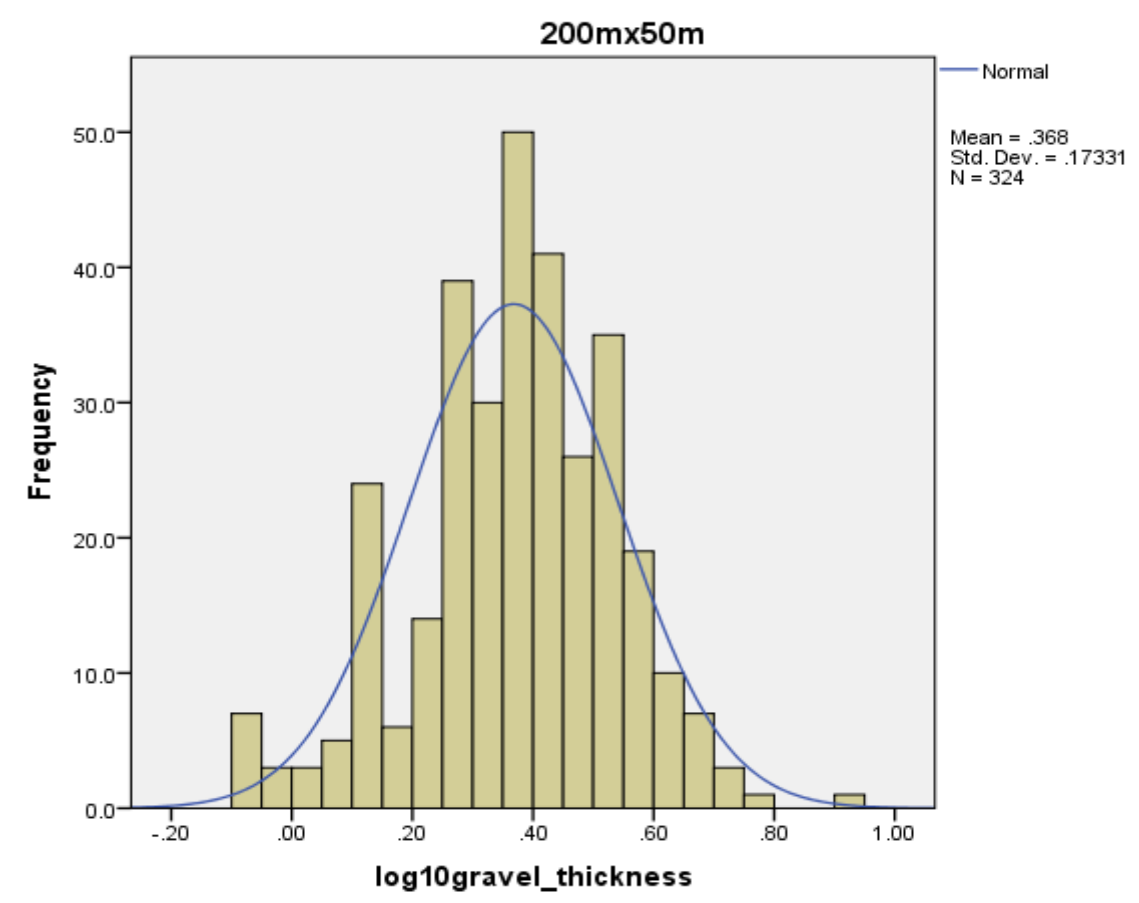

Fig 9. Log transformed of the gravel thickness with indications of normal distribution.

Table. 1

\begin{tabular}{|l|r|r|r|}
\hline \multicolumn{4}{|c|}{ DESCRIPTIVE STATISTICS (No of samples=324) } \\
\hline STATISTICS & GOLD GRADE(g/m3 ) & Gravel thickness(m3) & 2.519 \\
\hline Mean & 0.4881 & 0.9979 \\
\hline Standard deviation & 0.393 & 0.996 \\
\hline variance & 0.155 & 1.272 \\
\hline Skewness & 1.961 & 4.713 \\
\hline Kurtosis & 5.557 & 8 \\
\hline range & 2.73 & 0.8 \\
\hline minimum & 0 & 8.9 \\
\hline maximum & 2.73 & 816.2 \\
\hline sum & 145.2 & \\
\hline
\end{tabular}

\subsection{Resource estimation}

All log transformed data were back transformed for the purpose of resource estimation. The results of the gold resource are shown in the equation below. The gravel thickness and Au grade used for the calculation were derived from the IDW using the surfer software with the power of 2 as indicated in Table 2 . The area was calculated from the polygon around the pit holes in Fig 10 using the MapInfo software. The area covered is $7.55 \mathrm{Km}^{2}$.

Table 2. Root mean square error (RMSE) and Mean from the IDW model.

\begin{tabular}{|c|c|c|c|c|}
\hline \multicolumn{5}{|c|}{ RMSE and Mean from the IDW Estimation } \\
\hline & & grade & Grave & thickness \\
\hline & Mean & RMSE & Mean & RMSE \\
\hline IDW, $\mathrm{p}=2$ & 0.46 & 0.05 & 2.56 & 0.21 \\
\hline
\end{tabular}




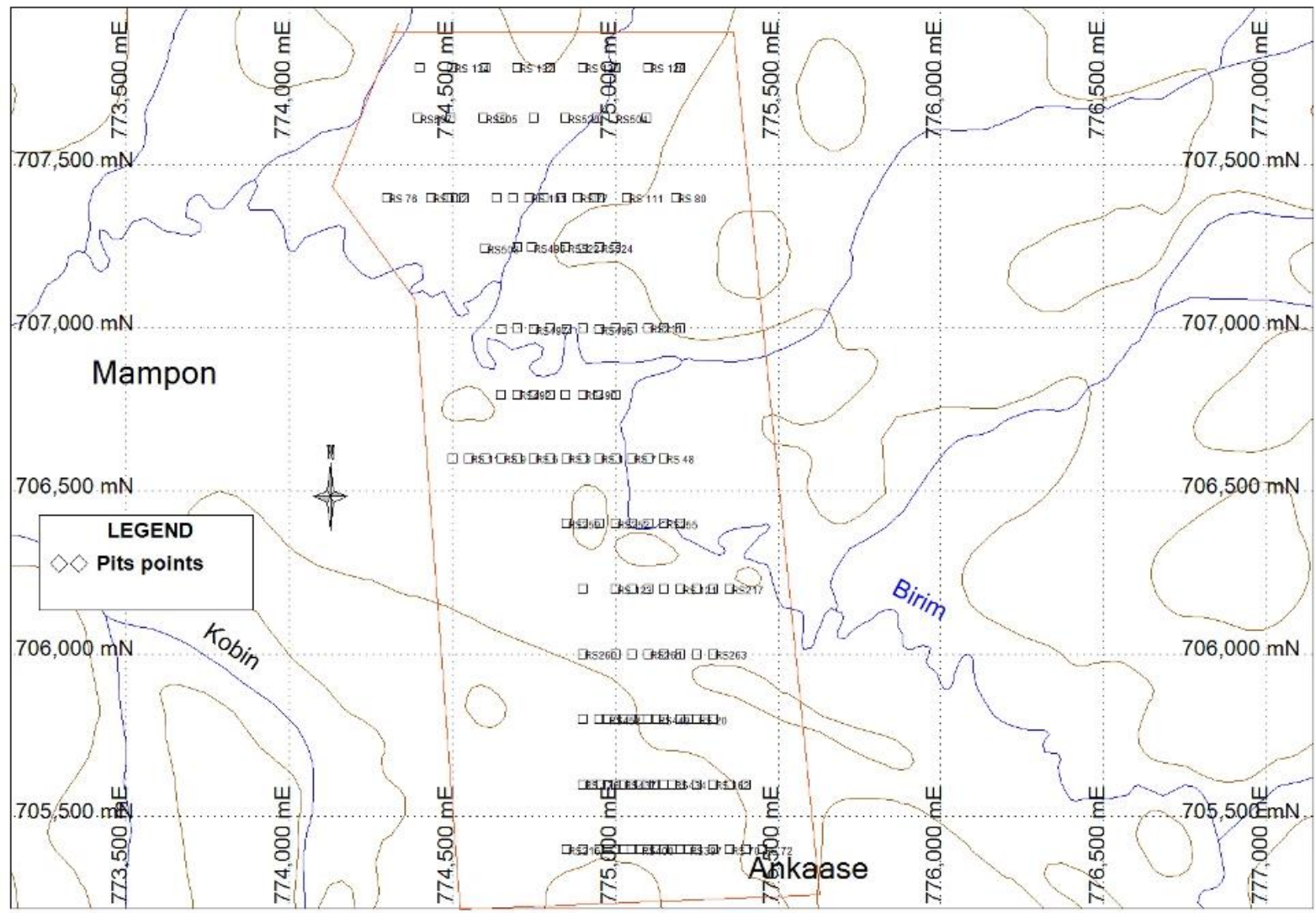

Fig 10. The pit holes within the study area. The area is $7550000 \mathrm{~m}^{2} / 7.55 \mathrm{Km}^{2}$.

$\mathrm{P}=\mathrm{GV}, \mathrm{P}$ is the resource potential, $\mathrm{G}$ is the mean grade of the gold grade model which is $0.46 \mathrm{~g} / \mathrm{m}^{3}$ and $\mathrm{V}$ is the volume of the deposit.

Volume of deposit=Area $\mathrm{X}$ mean gravel thickness

$\mathrm{V}=7550000 \mathrm{~m} 2 \times 2.56 \mathrm{~m}$

$\mathrm{V}=19328000 \mathrm{~m}^{3}$

$\mathrm{P}=19328000 \mathrm{~m}^{3} \times 0.46 \mathrm{~g} / \mathrm{m}^{3}$

$\mathrm{P}=8890880 \mathrm{~g}$

This estimated resource with value $8890880 \mathrm{~g}$ of gold may contain some impurities, so it was converted based on the purity of gold reported by Kwaben Mine as well as those purity of gold reported by Precious Minerals and Marketing Company (PMMC) from the study area. The purity from the area is noted to be $92 \%$. Using a purity value of $92 \%$, the gold resource was estimated as indicated below;

At $92.0 \%, \mathrm{P}=8890880 \mathrm{~g}$ X0.92

$\mathrm{P}=8179609.6 \mathrm{~g}$

$\mathrm{P}=261,728 \mathrm{oz}$

\subsection{DISCUSSION}

The hand dug pitting has provided the best technique for sampling the alluvial deposit. For major alluvial gold deposit evaluation in the country and elsewhere, Banka drilling has been used which sometimes give poor sampling representation (Rae et al., 2006). The hand dug pit used in this study is seen as the best method for sampling alluvial deposit and this can be use elsewhere especially where the depth of the deposit ranges to a maximum of $8 \mathrm{~m}$. Beyond this depth, it is not preferable to use this method. The grid density $200 \mathrm{~m} \times 50 \mathrm{~m}$ for the pitting has recorded the same standard error as indicated in the Fig (11) with other high dense grids $(100 \mathrm{mx} 50 \mathrm{~m}, 50 \mathrm{mx} 50)$ and is term as optimum grid density for evaluating placer deposit. It is only preferable, may be under some consideration to reduce to much closer grid in upstream areas where the grade seem to be high.

The various section which span from the overburden, gravel section to the bedrock comprises of different geologic materials. The reddish brown clay/silty component of the alluvial deposits may have been formed by the weathering of the rocks of the Kibi belts rocks which comprises of metabasalts, phyllites, greywackes and quartz veins. The clay may be characterized by the minerals smectite, halloysite, chlorite and vermiculite as they are the main products of weathering of such rocks as discussed by Richard et al., (1987). 


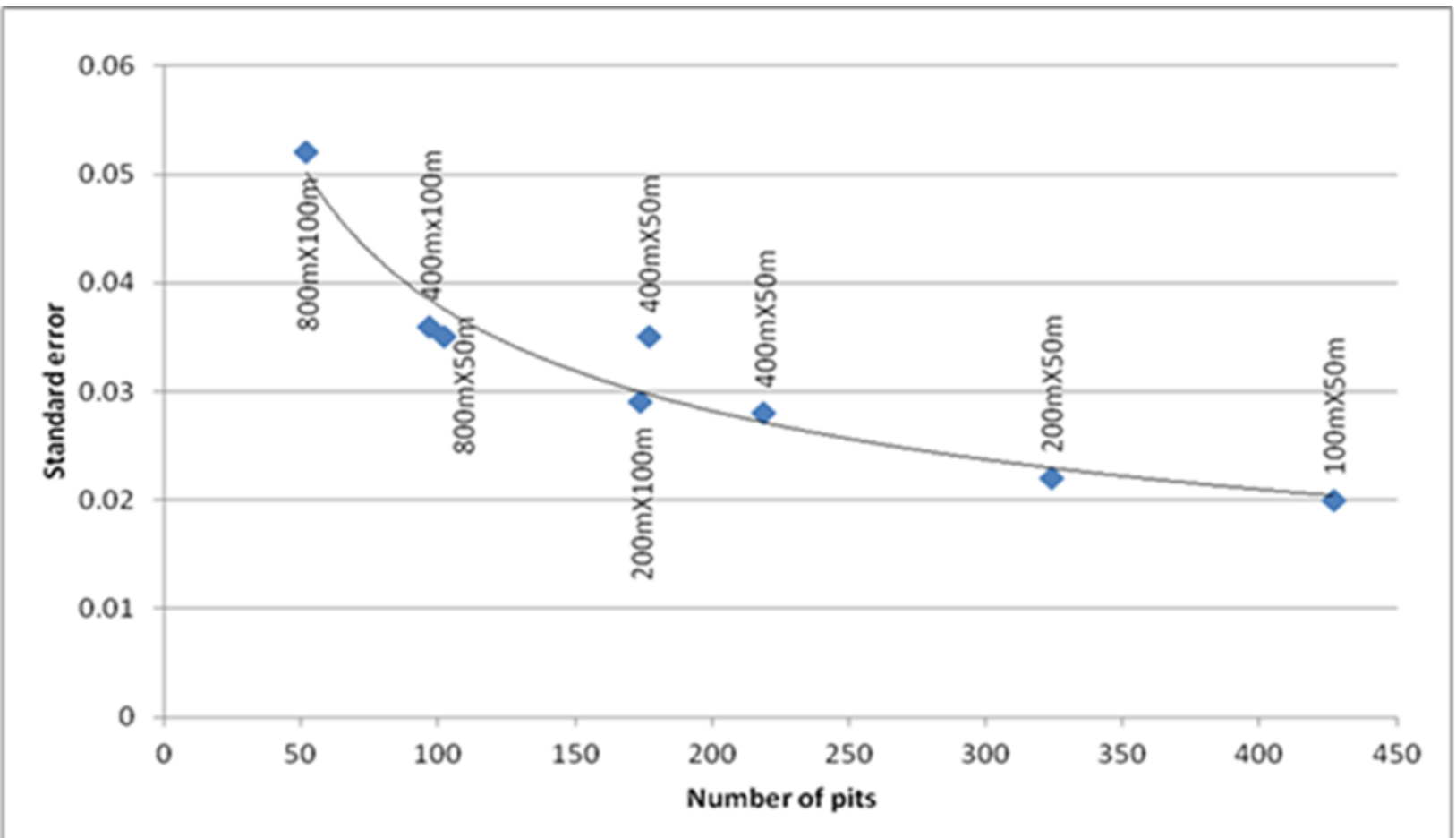

Fig11. Optimization plot of number of grid densities against standard error

The lateritic sections occur through the overburden and also within the gravel section. The small quartz pebbles found within the laterites maybe due to the quartz veins resistant to weathering found within the phylites or the metabasalts of the Kibi belt rocks. Laterites formation have been favored by the various rocks types, climatic conditions and the geomorphic features within the area. The composition of the laterites could likely be hematites, gibbsite and limonite which reflects the direct weathering/alteration of the minerals olivine, pyroxene, ca-pagioclase, K-feldspar and biotite. The hematite may have been formed from the alteration of the minerals; Olivine, pyroxene and biotite whiles that of gibbsite may have been formed from the weathering of Ca-plagioclase, and $\mathrm{K}$-feldspar.

The gravel section is characterized by quartz pebbles together with silty clayey or laterites in some areas. This is the mineralization section and contains gold of different sizes as observed by earlier prospectors (e.g Griffis et al., $1989 \&$ Rae et al ., 2006). The mineralization of gold within such layer brings to mind two different types of enrichment. Gold particles eroded and transported together with the gravels and later deposited within the are. Secondly, gold mineralization which formed as a result of continues weathering of mineralized rocks in in-situ. These two mineralization maybe differentiate based on the nature of the encountered gravels within the section. Those gravels carried from elsewhere may have developed roundness whiles those formed in-situ or near to the source may have some angular shapes.

The estimated resource potential is based on the $92 \%$ purity of gold within the area that has been reported by Kwaben Mine themselves and also from the PMMC reports of gold purity from the area. At this purity, the gold resource within the study area has been estimated to be $261,728 \mathrm{oz}$.
This estimation has been solely based on the $200 \mathrm{~m} \times 50 \mathrm{~m}$ pitting interval which is term as the optimal pitting interval for the Kwabeng placer gold $\mathrm{T}$ deposit.

The determination of the processing parameters from logging of the deposit is very important as they render processing difficulties. The clay materials associated with alluvial deposits is one of the minerals considered before setting up the wash plant. Too much clay slows the throughput rate and thus lower the amount of gold recovered in an hour per washing leading to reduction in general quarterly production rate.

\subsection{CONCLUSION AND RECOMMENDATIONS}

\subsection{Conclusion}

The Kwabeng placer deposit evaluation has primarily been based on the logging parameters from the hand dug pits. The hand dug pit provided representative samples for the purpose of the resource evaluation and deriving key processing parameters like gold grain sizes, clayey content, gravel sizes and silica cemented medium.

Also the $200 \mathrm{mx} 50 \mathrm{~m}$ was used for the estimation of the resource which is seen as the optimal sampling density. In the overall evaluation process, it is established that the Kwabeng deposit contains much clay materials within the gravel sections (ore zone) with gold grain sizes decreasing downstream. The total resource estimate for the study area include $19,328,000 \mathrm{~m}^{3}$ volumes of gravels with average grade of $0.46 \mathrm{~g} / \mathrm{m} 3$ and estimated fine gold of 261,728 fine ounces.

\subsection{Recommendations}

It is recommended that additional studies be conducted within the area to provide a spatial model of the variation of the clay content within the mineralized zones as well as 
the spatial distribution of the gold grain sizes, as it provide the basis of building the alluvial wash plant. It was observed that some areas recorded much lower values of gold grade which affected the final estimated mean gold grade value. In future studies, such low grade areas must be block and resource estimate provided separately for such areas. This will provide a more detailed resource estimate of the area under study amidst high variation of gold grade within the area.

\section{REFERENCES}

[1] Al-Hassan S.and Adjei D. ( 2015). Competitiveness of Inverse Distance Weighting Method for the Evaluation of Gold Resource in Fluvial Sedimentary Deposits; A case study of the Tarkwaian Deposits. Journal of Geosciences and Geomatics. Vol 3,.No(5), 122-127.

[2] Amar, D.R.; Koki Y., Megh R. D. and Krishma, D. (2014). Effects of Rock, Clay Mineralogy and Geological Structures in the Formation of Large Landslide, a Case Study from Dumre Bsei Landslide, Lesser Himalaya Nepal. Unpublished Report.

[3] Bookstein, R. (2013). Exploration and Evaluation Method to Gold in Alluvial deposits.

[4] https:/riouerte.comBoris, S.K. and William E.R. (2005). Reort on Placer Gold Properties in the Tuul Valley, Zaamar Goldfields, Mongolia. Prepared for Khan Resources, 2005. Unpublished Report.

[5] Chirico, P.G., Malpeli, K.C., and Moran, T.W., 2013, Reconnaissance investigation of the alluvial gold deposits in the North Takhar Area of Interest, Takhar Province, Afghanistan: U.S. Geological Survey Open-File Report 2013-1180, 14 p., http://pubs.usgs.

[6] Griffis, R.J. (2002).Gold Deposits of Ghana, Minerals Commission, Accra.

[7] Griffis, R. J.(1998).Explanatory Notes- Geological Interpretation of Geophysical Data fromSouthwestern Ghana, Minerals Commission, Accra,51p.

[8] Griffis R.J., Agyeman K., and J.A Rae J.A., (1989). History of the Goldenrae Alluvial Gold Project. Unpublished paper.

[9] Hilson, G. (2002). Harvesting mineral reaches; 1000 years of gold mining in Ghana. Resource Policy V28, 13-26.

[10] Howarth, R. J. (1984). Statistical applications in geochemical prospecting: A survey of recent developments. Journal of Geochemical Exploration, v 21, pp 41-61.

[11] Isaaks, E. and Srivastava, R. (1989): An Introduction to Applied Geostatistics, Oxford University Press Inc., New York, $561 \mathrm{p}$.

[12] Jonas, D.T. W., Sylvester G., Yannick S.G.DjibrilK. N(2018). Geostatistical and GIS analysis of alluvial gold content in Ngoura- Columines, Eastern Cameroon: Implications for the exploration of primary gold. Journal of African Earth Sciences.142, 138-157
[13] Junner,N.R.,1935.Goldin

the Geol.Surv.Mem.4,67p, Accra.(reprinted 1973).

GoldCoas

14] Luebe,A., HirdesW.,Mauer R., and Kesse G O., (1990). The early Proterozoic Birimian Supergroup of Ghana and some aspects of associated gold mineralization Precambrian Res, 46 $139-165$.

[15] Luebe, A and Hirdes, W, (1986). The Birimian Supergroup of Ghana ;Depositonal environment, structural development and conceptual model of early Proterozoic suite BundesanstaltGeowissRohstoffe, Hannover, unplubl rep, 259 pp

[16] Davis, D.W., Hirdes, W., Schaltegger, U., Nunoo, E.A., (1994. U-Pb) age constraints on deposition and provenance of Birimian and gold- bearing Tarkwaian sedimentsin Ghana West Africa. Precambrian Res. 67, 89-107.

[17] Tobler W. R. 1970. A computer movie simulating urban growth in the Detroit Region. Economic Geography. ;46:234 240.

[18] TulayT., IhamiB., FiratAt., and Ihami U., (2015). Assessment of Inverse Distance Weighting(IDW) Interpolation on spatial variability of selected soilproperties in the Cukurova Plain. Journal of Agricultural sciences, pp 374-398.

[19] Simon, M.S., Amanor J. and Byrne D. (2012). Independent Technical Report on Apapam Concession, Xtra Gold Project Eastern Region (2013). Unpublished Report.

[20] Lavich R.A. (2010). Alluvial Gold mining, Offin River Area Ghana. Unpublished Report.

[21] Rae, J. Griffis R.J., AgymangK.(2006). Evaluation of the Kwabeng, Pameng and Apampam. Alluvial deposits. Report Prepared for Xtra-Gold Resources Corporation.Unpublished report.

[22] Rae, J., Griffis R.J., Mosses J.R., (2009). Proposal For the Development of the Osino Alluvial Gold Project. Summited to WyomingMining andExploration.Richard, A.E., Chris F., and Dane Varkevisser (1987)

[23] Weathering of Basalt; Changes in Rock Chemistry and Mineralogy. Clay and Clay Mineralogy, V35,N3 161-169.

[24] Robinson, T.P., \& Metternicht G. (2003). A Comparison of Inverse Distance Weighting and Ordinary Kriging for Characterising within-paddock Spatial Variability of Soil Properties in Western Australia, Cartography, 32:1, 11-24

[25] Salman A.. Khali I. Ghazi Saffarini., Mohammed A.(2009). Geostatistical Calculation for clay reserves in Azraq Basin in Jordan. Journal of Geography and Regional Planning Vol.2(5), pp, 144-153

[26] Simon, M.S. ; Amanor J. and Byrne D. (2012). Independent Technical Report on Apapam Concession, Xtra Gold Project Eastern Region (2013). Unpublished Report Torkornoo, S Griffis R.J., Agyemang K. (2009).Assessment of an Alluvial Gold Mining Project Atewa Range Ghana, west Africa for Hawk UraniumInc.Toronto,Canada. Unpublished Report.

[27] Webster, R., Oliver, M.A., (2001). Geostatistics for Environmental Scientists. Statisticsin Practice. Wiley, Chichester, p. 265 